\title{
Leadership Practices in Effective Schools in Disadvantaged Areas of Canada
}

\author{
Yamina Bouchamma \\ Fondements et Pratiques en Éducation, Faculté des Sciences de l'Éducation, Université Laval, 2320 Rue des Bibliothèques, \\ Québec, QC, Canada G1V 0A6 \\ Correspondence should be addressed to Yamina Bouchamma, yamina.bouchamma@fse.ulaval.ca
}

Received 7 September 2012; Revised 4 November 2012; Accepted 6 November 2012

Academic Editor: Hoi Yan Cheung

Copyright (๑) 2012 Yamina Bouchamma. This is an open access article distributed under the Creative Commons Attribution License, which permits unrestricted use, distribution, and reproduction in any medium, provided the original work is properly cited.

Purpose. The purpose of this paper was to examine leadership practices in effective schools located in economically disadvantaged areas of three Canadian provinces: Ontario, Québec, and New Brunswick. Research Design. Our study was conducted in five successful schools selected on the basis of student outcomes on province-wide standardized exams, as well as on some risk factors such as rural area, low socioeconomic level, and proportion of Francophones (Ontario and New Brunswick). To increase the study's validity, we used triangulation and various data sources: (1) individual interviews; (2) observation of school principals; (3) field documentation; (4) student essays; (5) internal school documents such as mission statement, rules, and directives. Participants. Participants included Department of Education heads and school board administrators, school principals and vice principals, teachers, school counsellors, educational psychologists, parent school board members, and students. Findings. Results show that leadership practices in effective schools can be grouped together around five dimensions: establishing goals and expectations; strategic resourcing; curriculum planning, coordination, and evaluation; promoting and participating in teacher supervision and development; ensuring order and support.

\section{Issue and Context}

The purpose of this paper was to examine leadership practices in effective schools located in socioeconomically disadvantaged areas of three Canadian provinces: Ontario, Québec, and New Brunswick. The identification of effective leadership practices could be useful for the professional development of school principals who must overcome the socioeconomic and cultural determinism of students in these disadvantaged areas where the improvement of academic success for all remains a permanent challenge. Before the presentation of our results concerning the effective practices of our participants, we will present the three contexts of the study (Québec, NB, and Ontario), the literature related to leadership effect and effective schools, the theoretical framework of the study regarding the leadership effect on academic success, and, finally, our methodology.

Similar to the United States, with its "No Child Left Behind" policy predominant since 2001, Canada is also committed to the academic success of all of its students. This study addressed leadership practices in effective schools located in three Canadian provinces: Ontario, Québec, and New Brunswick. Despite being located in socioeconomically disadvantaged areas, these schools reported good outcomes in core subjects (mathematics and French) in their respective provincial standardized exams. In this particular context, reforms are not always a panacea, and social conditions can sometimes amplify the challenges which teachers face on a daily basis $[1,2]$.

An increasing number of authors emphasize the importance of applying teaching practices that have been proven effective [1]. In this regard, research on effective schools has shown the effect of leadership, educational methods, the monitoring of students' progress, as well as operational expectations and requirements for all students [3]. Despite the research on this subject, many authors maintain that the most complex changes in terms of school reforms are still in the black box [2]. While the positive effect of effective 
leadership on student achievement is an established fact, the way in which this leadership can make a difference, the degree of its effect, and the essential ingredients of an effective leadership are yet to be explored [4]. This study examined these leadership practices in three provinces where the academic achievement of every student continues to be a concern.

1.1. Academic Success in the Three Contexts. Improving public education and student achievement were top priorities for the Ontario Government during its 2004 and 2008 mandates [5]. In its plan entitled Leading Student Achievement [6], the objectives were, among others, (a) to provide principals with the necessary means to help their teaching staff with their less successful students and (b) to conduct studies on effective schools in the Ontarian context based on the leadership effect on student achievement [4]. In other respects, the Office for Quality and Responsibility in Education (OQRE) contributes to improving the quality of education in Ontario. In addition, the Literacy and Numeracy Secretariat assists school boards to improve student outcomes. In this regard, a team of student achievement agents was designated to meet the province's objectives which were the improvement of their students' learning and performance in literacy and numeracy.

With its education plan entitled When Kids Come First (2007), New Brunswick laid down specific guidelines to improve student achievement involving all levels concerned by this particular issue. The province continued to refer to the broad lines of this program when the Canadian Council of Ministers of Education published the results of the national assessments, in which New Brunswick came last on the list, and recently, government officials mentioned measures on improving Francophone students' scores in literacy, numeracy, and sciences.

\section{In light of New Brunswick's repeated low outcomes on international and national assessments, we must act urgently and at an age as early as possible to place the emphasis on school readiness, which will guarantee success in school and in life [7].}

In Québec, the government provides the school system with official state-sanctioned administrative authorities to improve academic success. For example, the Conseil Supérieur de l'Éducation provides guidelines on educationrelated issues, analyses in this area, and programs such as the Stratégie d'Intervention Agir Autrement focusing on improving student performance in socioeconomically disadvantaged areas. Each aspect of this program focuses on this improvement process through orientations, objectives, adaptation of practices in schools and classes, and so forth. One of these objectives is to reduce school inequalities relative to students' socioeconomic status [8].

\section{The Literature}

2.1. The Leadership Effect and Effective Schools. Many studies have examined the effect of leadership on students' learning and achievement [9-11]. One group of authors considered this effect to be second only to the teacher's effect $[4,12]$. Studies on school success should be the cornerstone for any investigation on educational leadership and its effects on student outcomes, as leadership is a significant characteristic of effective schools. The leadership effect is considered to be indirect, with an impact stemming from many sources: the staff's motivation, dedication, and working conditions, the distribution of power among all of the actors involved in the school $[12,13]$, and the school's organisation and culture (Wahlstrom, 2004; [4, 14, 15]).

In their meta-analysis, Robinson et al. [14] showed that the impact of instructional leadership on student outcomes was three to four times greater than that of transformational leadership. Along the same lines, Anderson [16] demonstrated that the best outcomes in mathematics and language were linked to an instructional leadership, which has been part of the school culture for years. This kind of leadership focuses on providing evaluation and support for students, with particular emphasis on the promotion of academic events in the community [16].

Studies have produced different ways to categorise the topics. For example, the study by Silins and Mulford [17] on leadership in "learning-organisation" high schools revealed six dimensions pertaining to leadership practices that promoted organizational learning: (1) vision and objectives; (2) culture (the principal is committed to build a nurturing and trusting environment for staff and promot staff/student respect); (3) structure; (4) intellectual stimulation; (5) individual support (the principal provides moral support, appreciation, and constructive feedback); (6) the expectation of results.

Among effective leadership practices, other studies combine various factors such as success-oriented behaviour, transformational leadership, a preference for educationrelated tasks, staff principal, and effective time management [18]. School leaders can stimulate student performance daily on several levels: providing professional development for their teachers, responsibly delegating, encouraging empowerment, acknowledging responsibilities, expressing clear objectives and expectations, facilitating instruction, and effectively welcoming change [19]. Leithwood et al. [4] grouped effective leadership practices together into three categories: (1) established orientations, (2) staff development, and (3) reorganisation. Deemed to be at the heart of an effective leadership, these practices, although necessary, do not suffice in every situation. Hallinger and Heck [20] proposed a different categorization: (1) goals, (2) persons, and (3) structures and social systems.

In this particular domain, one the most exhaustive studies on effective leadership practices is from Robinson et al. [14]. In their meta-analysis on effective leadership practices, Robinson et al. [14] demonstrated five dimensions: (1) establishing goals and expectations, (2) strategic resourcing, (3) planning, coordination, and evaluation of teaching and the curriculum, (4) promoting and participating in teacher development, and (5) ensuring order and support. In the next section, we present a review of these five dimensions from investigations of the leadership effect on academic achievement. 
2.2. Establishing Goals and Expectations. Leadership can make a difference on student performance with an emphasis on well-defined academic and learning objectives [21-23]. Leaders in effective schools tend to focus more on communicating goals and expectations $[23,24]$ and informing the community about student achievement [23]. In effective schools, there is also a higher level of consensus among staff members regarding the school's mission, compared to the level observed in less effective schools [25]. These goals are integrated in the classroom routines and procedures [26]. In addition, effective principals are more likely to involve their teachers in decision making processes on education issues $[24,27]$. Among the predominant characteristics related to school performance are the monitoring of the students' progress [3] and the importance of establishing clear goals that are prioritized [11].

2.3. Strategic Resourcing. Few studies have examined the subject of strategic resourcing, although one did find, in contexts of high academic success, a reciprocal link between the school leader's established goals and the number of teachers hired by this principal [22].

2.4. Planning, Coordination, and Evaluation of Teaching and the Curriculum. Leadership in effective schools is characterised by an active supervision and a well-planned curriculum [23]. To get results, these leaders involve their staff in setting goals $[23,24,28]$ and participate actively in discussions with their peers on education-related issues [23]. In addition, they strive to establish a system and an environment that is conducive to improving both teaching and learning and welcome the participation of teachers and the school community in the decision making process. To improve student achievement in a school-based management context, two conditions are necessary: empowerment and leadership ([17], page 655).

2.5. Promoting and Participating in Teacher Development. The more teachers talk about the active involvement of their superior, most often the school principal in their professional development, the better the student outcomes [21]. Teachers in effective schools often mention the participation of their principals in informal discussions on problem-solving issues in teaching $[23,24]$. In so doing, these leaders have a key role in the school's communication network, which means that their advice is more likely to have an impact on the coordination of efforts in the school community [29].

2.6. Ensuring Order and Support. According to Robinson et al. [14], leadership in effective schools is characterised by an emphasis on establishing a secure and supportive environment that involves clear social expectations and codes of conduct [23]. In these effective schools, teachers consider leadership to be successful when it protects them from undue pressure from outside sources such as education officials and parents $[23,30]$. The effective leader has the skills to quickly identify and resolve conflicts before they get out of hand by ensuring order and by providing a nurturing environment, where conflicts among the personnel are rapidly and effectively addressed [31].

\section{Theoretical Framework: The Leadership Effect on Academic Success}

For the elaboration of our theoretical framework, we were inspired by the study from Robinson et al. [14] on leadership and student achievement.

3.1. Dimension 1: Establishing Goals and Expectations. Effective leaders not only determine the appropriate goals but also clearly communicate them to their staff and enlist their commitment to achieving these goals. Attention is also given to ensure a followup. The effective leader welcomes input from staff members and gets them involved in the goalmaking process with proper consensus and clarity.

3.2. Dimension 2: Strategic Resourcing. The word "strategic" signifies that the school's principal screens, hires, and mobilises resources around the school's established educational goals. This dimension in no way refers to the leader's abilities in terms of fundraising, grant proposal, or business partnership activities.

3.3. Dimension 3: Curriculum Management. Leaders in effective schools distinguish themselves by their personal involvement in planning, coordinating, and evaluating the curriculum. The four interrelated subdimensions regarding this factor are (1) the leader's active participation in discussions related to education-related issues, (2) the leader's collaboration with staff in reviewing and improving the level of teaching, (3) the leader's level of involvement in in-class observations and the required followup, and (4) the leader's commitment to make sure that their teachers systematically evaluate their students' progress.

3.4. Dimension 4: Teacher Supervision and Coaching. Effective school leaders not only encourage professional development among their staff but also participate in these activities as leader/learner in both formal and informal discussions. They are committed to their staff's professional development and improvement and are thus more likely to be perceived by their staff as a source of reference in education, which suggests that they are more accessible and knowledgeable of such issues.

3.5. Dimension 5: Ensuring Order and Support. Effective leadership centers on establishing a secure, supportive environment through a clear code of ethics and expectations. Teachers' academic and professional training activities are prioritised and protected from undue stress from external factors. This principal also creates a well-organised, nurturing environment both in the classroom and in the school itself, where the teachers feel safe, at home, and appreciated. 


\section{Methodology}

The methodology used in this study was inspired by the educational ethnography tradition whose goal is to describe beliefs, values, and practices of cultural groups and individuals in a given social context [32]. The educational ethnography perspective enables the researcher to understand the complexity of the underlying cultural and psychosocial forces in a specific situation and the relationship between the various elements involved in this situation. Each aspect finds its meaning in the context of a global structure, which is why understanding these various elements may be arduous if the context is not taken into account [33].

4.1. Participants and Data Collection Methods. Our study was conducted in five successful schools (1 to 5) located in socioeconomically disadvantaged rural areas of three Canadian provinces (Ontario, Québec, and New Brunswick). The schools were selected on the basis of student outcomes on province-wide standardized exams, as well as on some risk factors such as rural area, low socioeconomic level, and proportion of Francophones (Ontario and New Brunswick). To increase the study's validity, we used triangulation and various data sources [34, 35]: (1) individual interviews, (2) observation of school principals during a workday at school, (3) field documentation, (4) student essays, and (5) internal school documents such as mission statement, rules, and directives.

Semistructured interviews were conducted with each participant who was asked to express their views regarding their own practices as well as those of their principals. Each interview lasted between one and two hours and was recorded and transcribed. The school principals were interviewed using a method that enabled them to identify and to define their professional experience so as to better understand these practices [36-38]. Interviews were conducted with school principals (SP) $(N=5)$, managing directors of education (MDE) $(N=4)$, directors of education (DE) $(N=2)$, their assistants (ADE) $(N=3)$, teachers (T) $(N=46)$, school counsellors (CO) and psychologists (PSY) $(N=7)$, parent committee members (PCM) $(N=11)$, and students (S) $(N=265)$. School principals and vice principals spoke of, among others, management practices and their school's social climate. The managing directors of education, directors of education, teachers, school counsellors, and educational psychologists talked about a variety of topics: practices, perception of their role, perception of academic success, challenges they must face on a daily basis at school and the means they use in order to cope with these challenges, and relations with actors of the institution (staff, students, etc.) or linked to the institution (family, community, etc.). Parents expressed views on such topics as school management practices, their own practices, school social climate, and so forth. The students were asked to write an essay in which they described their school to a fictitious correspondent who would be attending their school the following year.

In Québec, the disadvantaged segments of the population were selected with what is referred to as the indice de défavorisation (MELS), where every school is classified on a scale from 1 to 10 , from the least to the most disadvantaged. For Ontario and New Brunswick, we used the Statistics Canada databases and selected item income of area households. For all three provinces, student outcomes in French and mathematics were considered and had to show a progression over the three years preceding the study. The school principals had to be in residence for at least three years. The study was evaluated by the Ethics Committee for Research on Human Subjects to ensure participant anonymity and data confidentiality.

4.2. Data Analysis. The transcripts of the interviews, observations, students' essays, and field notes were analysed with Atlas.ti (V 5.5) qualitative data analysis software. The coding was mainly elaborated with the categories of our theoretical framework, but we let the door open for emerging categories [39]. We have been in the obligation to make the following changes to the dimensions of Robinson et al. [14] after a close examination of our data: only curriculum in dimension 3 was used, and we framed dimension 4 with respect to teaching and the supervision of teaching staff. There were no changes for dimensions 1, 2, and 5, namely, (1) establishing goals and expectations, (2) strategic resourcing, and (5) ensuring order and support. As seen in Table 1, dimensions 3 and 4-(3) planning, coordination, and evaluation of teaching and the curriculum and (4) promoting and participating in teacher development—became, respectively, (3) curriculum management and (4) teacher supervision and coaching.

Once the data were coded, compared, and analyzed, we then considered the five dimensions of Robinson et al. [14] with a few changes to avoid the overlapping of topics during their categorisation, which regarded teaching as well as the curriculum.

Subtopics were developed from the content of each dimension, and we completed the five dimensions as needed with an approach centered on our data [40]. Phase one of our study centered on developing a descriptive table showing the most obvious practices used in each school, while phase two focused on the analysis of each individual case according to the different topics. Finally, general conclusions were drawn following a comparative analysis to identify the primary topics and commonalities. A sample from our data was coded by three persons. We then applied the principle of reliability by intercoding (between the three persons) and intracoding (to ensure the stability of each one within a specific time frame) [41].

\section{Results}

Our analytical framework is an adaptation of the Robinson et al. [14] study on leadership practices and effective schools. We identified five themes linked to leadership practices in the effective schools under study: establishing goals and expectations; strategic resourcing; curriculum management; teacher supervision and coaching; ensuring order and support. 
TABLE 1: Dimensions of Robinson et al. [14] with modifications.

\begin{tabular}{ll}
\hline Robinson et al. [14] & Our framework \\
\hline (1) Establishing goals and expectations & Idem \\
(2) Strategic resourcing & Idem \\
(3) Planning, coordination, and evaluation of teaching and the curriculum & (3) Curriculum planning, coordination, and evaluation \\
(4) Promoting and participating in teacher development & (4) Teacher supervision and coaching \\
(5) Ensuring order and support & Idem \\
\hline
\end{tabular}

5.1. Establishing Goals and Expectations. In order to set definite goals and expectations, the school team develops a plan involving (1) strategic planning, (2) annual operations planning, (3) progress reports, and (4) plan adjustments.

5.1.1. Strategic Planning. The teams responsible for the various programs establish their respective strategic plans. For example, the remedial education team lays down the goals and expectations of their program as follows:

For students who are experiencing learning difficulties, we have a team in remedial education that provides solutions to meet the needs of these students. We must have high expectations for these students, but we must also provide the appropriate solutions they need (5.SP)

At the beginning of the year, the school leaders establish clear goals and expectations and communicate them to the staff: "The first thing to do is to know where you go, a good idea regarding where you want to go, and to communicate this message clearly and precisely" (5.SP)

The following is another reference to this kind of planning:

When they develop their global orientations, the team has a meeting. They have regular meetings where they discuss, think about the vision and the core orientations to adopt. This is probably where they do their planning. The school principal helps his vice principals and makes sure to put the plan they have elaborated together into action (5.DE)

To ensure that this work is feasible, strategic planning development is linked to school planning, past achievements, and the different requests made by stakeholders as follows:

When the time comes to draw up the plan, it's often more than just jotting down on paper something that reflects the goals already established for the year... There are other things coming from the school council... to see what we have and to try to make sense of it all (1.SP)

The school principals stated that they try to optimise available resources and set goals to help maintain a level of enthusiasm among their staff. "You must help your teachers to want to or get them to tell you how to improve the situation" (1.SP)
5.1.2. Operations Planning. Following the drawing up of the strategic plan, the team meets with the teaching and nonteaching staff to discuss and validate whether the plan is operational and feasible.

Involvement of Teaching and Nonteaching Staff. School heads and team leaders begin by drawing up an initial draft of the plan. To validate its feasibility, the teachers then participate in the process of establishing priorities and strategies as follows:

In the last few years, we have sought to determine which domain should be our focus. The principals and team leaders then produce a draft along the global objectives they wish to achieve. Afterwards, with the teaching staff's collaboration, we try to see how we can reach our goals using those strategies (4.SP)

Presenting the Plan to Parents and Students. This improvement plan is related as much to the students' behaviour as it is to their academic success. The plan can also be used to establish the expectations of the students and is presented to them as clearly as possible to guarantee their commitment to the process. "The more this is explicit, I think, the more the student is able to be involved because he understands exactly what the expectations are" (1.ADE).

Staff and parents involved in the school's parents' committee are generally well informed of the quinquennial plan and the improvement plan for the new school year, and they receive the necessary feedback. Teachers meet with parents on opening day to present what the school expects from them as follows:

At the beginning, we have an "open house" where parents can come in and meet their children's teachers. In so doing, the teachers have the opportunity to do a general presentation of their objectives and, most importantly, the class regulations (4.SP)

5.1.3. Progress Reports. Principals in effective schools speak of the goals to reach while taking into account the government's policy. "It would take someone who could say, 'This is where we are headed. We have Department-established goals and we must work toward achieving these goals. So this is where we have to go"' (1.SP).

In order to control what works and what needs to be improved, effective principals do student followups at least once a week. "And every week, we check what we have 
achieved in the last week; how they are doing. We check each and every case" (1.ADE). When there are poor results, the principal meets with the student in order to help the latter to set their priorities as follows:

At the end of the semester, if the students fail in the core subjects, they meet with the principal who explains that it does not work like that in real life, that this is perhaps the time to start working and get their priorities straight for the future. If your priority is "I don't want to finish high school", this is not a good start. Or if your priority is "I want to finish high school", maybe it's time you established your priorities (3.T2)

The school principals' supervisors acknowledge the work done with their staff and the fact that their team is involved in the plan's followup as follows:

He regularly talks about his school's mission, the expectations of the school and the expectations of his staff. What he also does, with his experience, is be able, with a group of people, to analyse and dissect. He tries to develop new approaches that will help him maintain or improve the students' performance. This is what he does with his teams (1.DE)

One principal emphasized that it is important to often remind staff of the goal of academic excellence as the following:

As a school director, you must understand that you
will be criticized. You just have to keep reminding
them. Our priority remains the students' achieve-
ment. This is what we are all working toward, and
for this reason this is what I ask of you (1.SP)

Another school principal pointed out the importance of often going over the plan with the staff to keep them informed as follows:

\begin{abstract}
If I want my message to get through, if I want to make sure that they know where we are going, our plan is our bible. It's there to guide our actions. For teachers who have been here for 5, 7, or 10 years, I think they understand where we are going. The greater the rotation in the staff, the more you must keep working on your plan (5.SP)
\end{abstract}

School principals must reply to their district, and the same holds true for teachers who must report on their students' scores on provincial exams. When teachers get the results, they seek to improve the situation. "I always get them [the results] in September, October. How did my students do? How can I help them to improve? We discuss this a lot" (3.T2).

5.1.4. Plan Adjustments. Throughout the year, the team evaluates the plan, and adjustments are made throughout this period. The plan is therefore considered as a guide that can be both questioned and improved as follows:
For me, as principal, this plan is an essential tool. I look at it a few times a year with my staff. We take a half-day to assess the situation and develop a new plan in May. From there, we get feedback and we make adjustments according to what worked and what did not (5.SP)

I think we have developed a vision as well as clear goals to evaluate the factors that help our students learn. We also do regular reviews, which is the principal's job. Each time we look at it to see if we have reached our goals or if we need to proceed differently to do better (5.CO)

5.2. Strategic Resourcing. Strategic resourcing involves staff selection, hiring, and mobilisation.

5.2.1. Staff Selection and Hiring. While school principals do not have that much to say as to the selection and hiring of their teaching staff, some strive to secure the best possible candidates. "I know that in terms of the recruitment of new teachers in past years, we made it a priority to get the best ones available" (5.SP). This participant added that in addition to selecting new staff, he does not hesitate to let go of those who are not up to par as follows:

When I arrived, I had to let some members of my staff go, which is not an easy process. I laid off a secretary who worked at my school for 30 years. This is the message I wanted to convey. If you are not up to the task, you will not remain on my staff. There are teachers who have worked at my school for six years and I refused to give them a $B$ contract. I told them: "If you want to give a $B$ contract to this person, you will have to send her to another school." If there are teachers from other schools who want to come here, I will screen them (5.SP)

The principals emphasized that they surround themselves with a good team and delegate tasks to the right persons. "Among other things, you have to surround yourself appropriately, delegate appropriately, and make sure that the right persons manage the right issues" (1.SP). Parents also felt the same. Their children's principals select their staff well and know the importance of a strong support team. "Regarding his teaching skills, I think this is someone who knows how to be well-supported. He has been able to connect with the vice-principal, who was already at the school" (2.PA). The principals' superiors acknowledge their particular ability to optimise resources. For example, an education official explained that a school principal had to reduce from ten to four the number of administrative staff with responsibilities (PAR) in order to cope with the needs related to teacher supervision. "At that moment, the principal's role is certainly to support these people with what they have to do in their own sector. These principals are leaders who show that they are taking very good care of their school" (5.DE). 
5.2.2. Staff Mobilisation. Leadership in effective schools uses four levers to mobilize their staff: information, power, knowledge, and recognition.

Information. In effective schools, principals continuously share information with the various contributors. For example, the staff is very well informed regarding every aspect of their work. "In the beginning, he did a presentation of the project. We were given that information..." (5.T4). By receiving the same training, or when one member gets training and shares it with their peers, everyone is on the same page and speaks the same language, which greatly facilitates communication. Another teacher remarked the following:

\section{Our principal accumulates the information as the core source of reference, and there are teachers who will become multipliers with their peers. It makes it easier to share the message, and we have the same view. We will have different strategies (1.T5)}

Empowerment. Leadership in these effective schools focuses specifically on new teachers. The MDEs and DEs emphasized the fact that principals know how to help new teachers cope with their responsibilities and perform with greater autonomy.

Knowledge. Effective school leaders are able to guide their teachers to acquire knowledge related to their work. They encourage them to see out the appropriate training to improve their capabilities. In so doing, the teachers are better equipped to help their students improve their scores.

Recognition. The teachers mentioned that while their principals only rarely intervened with teachers who stray from the school's culture, they often took the time to acknowledge the quality of their staff's work as follows:

Yes, at this particular level, the principal remains available, although there is no formal evaluation. It's not just a slap on the hand, you could say. There is also the friendly little tap on the shoulder that means "Keep up the good work, you are doing well." We also get that and it makes you feel good (3.T3)

Teachers appreciate the fact that their principals show their appreciation of their work. "The principal values these projects as well as my students" (5.T9).

I feel the principal believes in what I'm doing. He sees my commitment to my work and the tasks that I consider priorities. When they give me new duties, they always ask me... I'm entitled to have my say and I always get feedback on what I am doing, and vice versa (5.CO)

5.3. Curriculum Management. Improving the curriculum is a team effort often supervised by the principal. When duties are delegated, the designated teachers receive the proper support. Any changes to the curriculum are preceded by a thorough student needs analysis.

5.3.1. Team Work to Improve the Curriculum. Principals and teachers work together on the curriculum. In one school that had begun integrating a guidance approach in its programs, the principal and teachers collaborated to initiate projects that involved in-class activities as follows:

We have a committee with ten teachers for this approach. I head this committee. Our goal is to move forward with this and to initiate projects. We are providing training and activities for the teachers which they can do in their class (5.SP)

Effective principals also delegate duties pertaining to the curriculum and provide their teachers with the appropriate support. They focus on more than just the contents, for example, a new course on learning strategies for students who have failed some of their courses. The principals took the initiative with this new course and identified the material and human resources necessary to develop it. "They [the principals] decided to offer this new course. They initiated the project. The role they have to play remains important, in the sense that they asked me to teach this course" (1.T4). The principals therefore provided the appropriate support to the person responsible for this course. "But I've received a lot of support from the vice-principal. I can always see her and she helps me all the time. She gives me suggestions" (1.T4). "He was a bit my expert in this project and gave me one hundred percent support. He even came in the morning I had a class and observed me the entire period. He was really happy with the project" (5.T4). Moreover, the effective principal remains open to what is going on elsewhere and occasionally provides help for at-risk students from other schools as follows:

In our school, for a couple of years now, we've had courses for area students who are experiencing difficulties. The principal was very open to welcoming these students, searching for the services they needed, things like that, to set up (5.SP)

5.3.2. Empowerment of Teachers. The teachers actively participate in the development of programs and various committees as follows:

Our staff is also involved in every possible committee at the provincial level, at the Department of Education level, as well as on the committee in charge of program development. At the high school level, we have just experienced reforms along with new programs (5.SP)

5.3.3. Evaluating and Responding to the Students' Needs. Principals in effective schools propose changes and adjustments to adapt the curriculum to the students' needs to ultimately achieve better results. The participating principals enumerated many such actions, such as transforming a noncompulsory test into a test where the outcome counted 
in order to motivate the students and creating a voluntary remedial class for 8 th grade students with poor grades to help consolidate certain core concepts.

The principal's practice therefore centers on finding appropriate solutions to the inadequacies within their environment. Such is the case, for example, in regards to help with homework; the principal looks at the students' records, determines the needs, and introduces a new project to respond to these needs. The principals interviewed did acknowledge, however, that to a certain extent, help with homework is limited by the family context as follows:

Parents have trouble helping their children with homework, and all of that. So, as the principal, there is no question that we keep an extremely close eye on the students' record.... So we encourage a lot of remedial classes during lunchtime (2.ADE)

To reach this goal, the community is invited to contribute to raising the students' level of competency. For example, the Caisse Desjardins provides financial support for students tutored by their peers. "We initiated with Desjardins its Desjardins Mentoring Project, whereby students from grades 4 and 5 are paid by Desjardins to help their younger peers who are experiencing difficulties" (2.ADE).

5.3.4. Integrating New Services. Principals do not limit their actions to reorganize weekly schedules but also introduce new services to help with students' needs in mathematics. "We have just introduced the Saturday school... Our focus is first and foremost in mathematics for this year. But it could be extended to other subjects later" (2.ADE).

5.3.5. Review and Improvement of Curriculum Schedules. Effective principals review course schedules for optimised results. One experience mentioned pertained to linguistic skills which were introduced gradually in chronological order to obtain better scores on the linguistic skills test as follows:

We were talking about the fact that we would like to see all of our 10th graders at least at a level equivalent to the beginning of their 10th grade course before they pass the test. We placed all of our French courses in the first semester for the 10th graders... so our students finish the 10th grade French courses before they do the test in March (1.SP)

The approach is personalized to meet individual needs, such as, for example, with students who require assistance in mathematics as follows:

With the reforms, we also managed to maintain our support in mathematics for the 7th grade, which means that we took out two periods in arts for students with learning difficulties in mathematics in order to give them two additional periods in math. So, with these two additional math periods, remedial class at lunchtime, Desjardins mentoring.... We think the children have a better chance of succeeding (2.ADE)
5.4. Teacher Coaching (Supervision). This aspect could be divided into two subtopics: differentiated teacher supervision (according to their needs) and professional development strategies. New teachers are a top priority. The interviewed teachers spoke of the support they received from the principal at the beginning of their career by helping them with in-class discipline or being present in the absence of any real social network. "When you first arrive and you're not from the region, you do not know this particular culture.... The principal meets you a bit more often to check on how the things are going" (3.T2).

\section{Another teacher's account was similar to what was mentioned by some of the principals as follows:}

The teaching staff at $X$ high school is also very, very young. Despite this situation, he has been able to provide coaching and supervision and has made sure that his staff is appropriately trained for what they have to do (1 and 5.MDE)

5.4.1. Differentiated Coaching. As school principals do not have much say in the selection of their teaching personnel, they choose to focus on their teachers' professional development in both formal and informal training activities.

Supervision by the Principal. The teachers undergo a formative evaluation aimed at improving their skills. The teachers themselves identify their needs regarding supervision and base their requests accordingly as follows:

I won't call it evaluation. Let's say, I'll call it coaching. The door of the principal's office is always open for students and teachers who are having difficulties. But you know... This is not a formal evaluation. We do not get a paper with how to succeed. On the other hand, we do get good feedback (3.T2)

The teachers emphasized the importance of their principal's feedback following in-class observations which enables them to put their actions into perspective. "I appreciated these suggestions because sometimes we get so stuck in our routine that we do not notice what we are doing wrong, or what we can improve" (1.T1). Some teachers mentioned that they made changes following their discussions. "I made a few changes, positive ones, small changes which I as a teacher would have never seen" (1.T7).

Self-Evaluation and Expert Training. Other types of evaluation are proposed. Teachers in effective schools are encouraged to identify their needs and convey them to the principal who then follows up with them. The teachers felt that their principal backed them up in their projects whenever possible. "I always got the support I needed for the activities that I wanted to do" (5.T5).

Another participant spoke of this support by the principal as follows:

At the beginning of the school year, each teacher has an individual plan. It's an annual plan, a sort 
of inventory of their training needs which they submit to us. From this, we can better identify some of their needs. But a lot of it is also informal. People come and talk to us (1.SP)

Effective leaders encourage their teachers to think about their practice (reflexive practices). In this regard, they are supported by the PAR as follows:

\begin{abstract}
Myself, as school principal, to allow them to grow, I do a lot of reflexive activities at the personal growth level.... I have a team with me, pedagogical professionals with administrative responsibilities (PARs) who will help their respective team grow (5.SP)
\end{abstract}

Teachers seek training to help meet some of their students needs. They identify their needs, formulate them, and justify them before the principal to receive good feedback from them and obtain expert help from outside. "In other words, it's all about preparing teachers to meet the program's objectives in different ways. We found that this was a relevant way to do so" (4.SP). Various types of professional development are envisaged. When internal resources do not allow for training by peers, the principals welcome outside help. "In other words, we occasionally invite a guest speaker to come in for group discussions with our personnel, the teachers in particular" (3.SP).

On the other hand, the principals are encouraged by province heads to attend their teachers' training activities so as to train themselves regarding the various aspects that they must evaluate with their teachers. "Well, for me, I hope that our school principals participate in the same pedagogical training sessions as the teachers, to be better able to evaluate them" (2.MDE). This view is well received by both principals and teachers as follows:

The message gets across much better this way. And we also have the same vision. We are going to have different strategies. So as in this case, this is something that the principals here do a lot. It's really great (1.T5)

Peer Supervision. Teachers often present their training needs informally. In each case, the need for training may be addressed by internal resources (peers) or by external experts. "What we try to do is to provide training where staff members share their expertise with others" (1.SP).

5.4.2. Means Used for the Teachers' Professional Development. In general, several means are deployed to support professional development.

Resource Availability: A Prerequisite. Effective principals ensure the availability of resources to support their teachers with their proposed projects. "... the principal, when they know that a project is to be brought to fruition, is able to support it as long as it's clearly defined and well-presented" (5.T5).
Principals can occasionally lessen a teacher's workload for professional development purposes to enable the latter to reflect on the goals reached and the work ahead. This is highly beneficial as it encourages discussion and strengthens the bond between principal and teacher as follows:

We allowed teachers one full afternoon with me, and we talked about reform.... What was going well? What did they feel they should continue to work on? What was bothering them? What did they find tiring? What questions did they have? They really appreciated it (2.ADE)

Teachers are also allowed to attend training sessions that are tailored to their specific needs. The principals are aware that their teachers cannot train themselves if they are not relieved of their duties as follows:

I find that it is taxing for teachers when schools continue to function and they must leave for training.... In these cases, the teachers feel more relaxed, are ready to work harder, and do not have to worry about the whole question of their replacement $(4 . S P)$

Supervising Supervisors. Although their teachers are peerevaluated, the principal does the necessary followup with the supervisors to oversee their professional development as follows:

It's the role of the principal to see to it that their teachers are evaluated and that feedback is given in a reasonable amount of time, and that the follow-up be done later to see if the teacher has improved (4.T8)

The Department officials reiterated that the school principal was responsible for the whole aspect of supervision and that they remain in charge even when delegating duties to a third party: "People must certainly let him know what is going on. But each sector must see to providing the best quality in terms of the students' learning" (5.DE)

Collaboration between Teachers. During PD days, the principals train their teachers on the job using a collaborative approach by going over norms and procedures. Teamwork is encouraged as follows:
And so, we favour professional development days to enable teachers to meet. I have made presenta- tions to each sector to familiarise them with what teamwork is, what work method should be used, the work norms and an order of the day model" (1.ADE)

Nonjudgmental support is provided. Teachers who express their difficulties do not feel judged, as one teacher testified, with regard to class principal as follows:

Mr. X helped me a lot, especially in the beginning. $\mathrm{He}$ is always available, we often see him in 
the hallways. So when there is a matter we would like to discuss, he is available to meet with us. Because he knows the students well, if we have problems with discipline, we can talk to him about it. He encourages me (2.T3)

In certain situations, the principal intervenes between the teacher and the parents. Because of the principal's support in problem situations, their teachers are able to motivate their students to perform better. "When we are supported, we know that we can push. We know that the parents support us, we know that our principal supports us and will intervene between the teachers and the parents if there are problems" (5.T3).

The teachers emphasized how important the role of their principal was for them. They mentioned appreciating the coaching and support because it respected their individual choices. "Principals have a huge part to play. It is absolutely crucial that the teachers feel that they are being supported by their principal.... It is important to get the message across that you support the teachers" (5.T3).

The principals support their teachers' projects, such as for example, pedagogical initiatives as follows:

We always feel that our principal is there to support us. Then it shows in the teachers' pedagogical projects. I find that this makes a big difference, particularly for new teachers who are in the process of integrating within the school. They do not always know how well to manage (1.T7)

The support provided by principals for new teachers greatly contributes to their adaptation: "I think that here, in school $X$, it's easy to adapt because the principal is very present" (1.T7).

5.5. Ensuring Order and Support. The quality of life in a school is expressed through several interdependent components. We identified three themes based on our data: rules, communication, and interpersonal relations.

5.5.1. Rules: Supervision and Control. The rules most often evoked by our participants regarded attendance and discipline.

Attendance. Our participants stated that they demanded that students show up and be punctual, naming punctuality as an important value on the job market as follows:

If you say to your students, "You have to show up, and you have to be punctual" and all that.... Because in the workplace, if you want to be a good employee, well, you have to be on time (5.SP)

Several effective schools have zero tolerance regarding all forms of unjustified absences. One participant stated that the school had a detention policy at lunchtime for all unjustified absences which were managed by a computerized system that transmitted the information to the teachers and principal via their laptops as follows:
There are detentions every noon hour with a supervisor. They even built up an easy laptop system in which the name of the student is entered and we can check the next day to see if the student was present. The principal does the follow-up. It's working like a charm this year (4.T2)

In effective schools, the students also recognize that their school has a good absence and detentions system (1.S)

Discipline. Certain participants said that they liked rules that made it easy for them to manage discipline in school. "We have a little rule starting this year that has changed the atmosphere in the school" (4.T2).

Explained and Enforced Rules. The student participants stated that the school rules are clearly explained to them and that the principal is present during lunchtime to oversee security. "The principal sees to it that our integration and stay at the school is very safe.... We learn to become one big family" (1.S).

Individualised Consequences. The principal not only applies the rules regarding attendance and punctuality, but also adapts them to specific situations. For example, the rule regarding suspension after a certain number of absences does not apply to students at risk of dropping out. Suspensions are therefore applied according to the profile of each student as follows:

The policy of attendance and punctuality with recommendation for suspension used to be automatic after a certain number of absences.... When they leave once, even if they return, it's always more difficult to return. Because they find that they have fallen behind academically, and find themselves the next year with students younger than themselves. Then they look for a way to drop out (4.SP)

Resolving Conflict: Means and Strategies. Several means are used to ensure the compliance with school regulations. Certain schools use a penalty system (two lessons not done equal one penalty). In this system, the goals and the rules are clearly explained to the students as soon as they miss the first time, which obliges them to conform to the system as follows:
Look, we are taking this seriously this year. We want this to work. And we have presented the system to students. Furthermore, the system is not complicated, has two quick stages, and already at the second slip-up there is a penalty. So the student is forced to wake up, to take responsibility. That is an indispensable form of support (3.T5)

Support by the Principal in Applying Discipline in Class and Reducing Apathy. While recognizing that teachers are responsible for discipline in their class, the latter agree that it is a shared responsibility between all members of the school. 
Teachers also reiterated the importance of the principal's support, particularly in social contexts where certain families are permissive as follows:

\begin{abstract}
I know that the teacher has the primary responsibility for the atmosphere in his classroom, but I have the right to work in an atmosphere conducive to learning, in an acceptable climate. I can do my part and the students must do their part, with the support of the parents. But we also need the principal's support. We are in difficult times: Children rule the home (5.T10)
\end{abstract}

Principals also intervene in cases of student apathy to "jump-start students who refuse to work." The teachers stated that in all of the schools, the principal supports them in cases of disrespect of the rules regarding discipline. "If we have a problem with a student, our principal takes the lead and backs us up" (2.T1).

The teaching and nonteaching staff, students, and principals in the effective schools all stated that their school's climate was both nurturing and safe. The teachers mentioned different situations where the principal helped them to establish a new class climate by solving violence issues, whether active or passive. For example, when a student refused to partake in class activities the following happens:

\begin{abstract}
A student who does not want to work, participate and all that, we know that our principal is going to be behind us and support us, and the students know it. Therefore, I would say that yes, they do have an influence, and it helps us (3.T10)
\end{abstract}

The students agreed that the principal's team played a big role in dealing with bullying at school. "They do all that they can to please everybody and everything within their power to stop the bullying" (1.S). They also reported that their principals were present on a daily basis to supervise at lunchtime. "They supervise most of the time, see to it that the school functions for the benefit of all of the students" (1.S). As for the various strategies used, one school principal (2) encourages the students to write one paragraph a month under supervision on the subject of the school atmosphere, to express what they saw, heard, or experienced with regard to bullying.

Accessible and People-Oriented Principals. Principals of effective schools have no qualms about losing control by being too close to their staff. To maintain control, no distance is created between themselves and others in their school because they know how to go from one style to another. Although they remain accessible, they know how to maintain their authority to resolve problem situations as follows:

Well, when I'm in the school at lunch hour, I chat with you, it's quite pleasant. We know each other. We learn to discover new things. On the other hand, I have another role to play. If you did something stupid in your class, I'll have to intervene and that's the way it is (2.ADE)
The teaching and nonteaching staff underlined the availability of the effective principals; that it was easy to go and meet with them informally, without having to wait for official meetings or for serious problems to rise to do so. Problems were resolved on a day-to-day basis as follows:

\begin{abstract}
Me, I go meet the principal. It's just like going to the cafeteria. I can go see him, he is available. I will go and talk to him about a student, "Here is such and such a thing that we could do for such and such a student". It does not have to be a student who is in major trouble. It's the same thing with the vice-principal; I spend lot of time on rounds and generating different types of solutions. The door is always open (5.PSY)
\end{abstract}

Principals are equally close to students. Parents attested to this fact. "If they have comments, worries, or questions, they [the students] feel comfortable going to see [the principal] and talk to him" (1.PCM6).

Being Proactive. Effective principals establish not only proactive strategies (preventative measures), but also reactive ones. They use proactive strategies to minimize the opportunities for bullying and provide training in this regard. They use proactive strategies to apply consequences already detailed in the directives, and they adapt them to the situation. They do not wait for the problem to happen to act. In addition to resolving existing problem situations, they have a proactive attitude with respect to violence issues. The students stated that the principal's team raised their awareness concerning violence in the school. "The principal's team integrates courses on discipline, violence, or behaviour that encourages better behaviour" (1.S). An effective team also helps the students to manage their stress (1.S).

Ensuring a Supportive Environment. Principals provide the students with the best possible working conditions each day and also during exams. For example, they will establish schedules that take into account the particularities of different subjects to limit noise and create a more positive environment (1.ADE). The principal is attentive and looks after others. In these schools, the principal is described by his qualities. "At the principal's level, I would say humanist. That is a word which comes up often. I speak with other teachers and the word characterises our principal very, very well" (1.T2). As for the principal, the latter is conscious of the importance of the human element. "The human side of things is very important. Being a good listener and having respect, that's important" (1.SP).

The student participants spoke of the daily encounters with their principals who stop and enquire how they are doing. "He makes the rounds at the school. He takes the time to talk to us and to find out what's going on" (2. S). The principal also takes the time to ensure that everything is going well by participating in their discussions. "He really likes to have discussions with us, to find out if everything is going well" (1.S). 
Effective principals are conscious of maintaining these interactions on a daily basis. With this closeness, the interviewed principals stated that they were able to communicate a message "to support them (the students) in their activities and to them that we are interested in them as persons at school as well as outside of school" (2.ADE). These principals do not limit themselves to a passive presence or simply discussions with the students, but occasionally participate in their students' activities as follows:

\section{Despite my age, I regularly go to the gym with the students. I make incredible connections with them. I participate in the student-teacher hockey game. I participate in all of the trips that the graduates take. I'm at all of the shows that the graduates put on (3.ADE)}

Both the students and the teachers mentioned that the students appreciate their principal's interest in their activities saying: ".. when the principal is there, when they get involved, is part of the various committees, the students like that" (5.T10).

5.5.2. Communication Methods. Principals in effective schools ensure quality communication and get involved when problem situations arise by maintaining the lines of communication open with all of their staff. Their staff and superiors agree. The teachers spoke of various teacherstudent, teacher-parent, and teacher-teacher communication networks. "The first quality of a teacher is to communicate well with his students. Communicate with the student, with parents too, and with other teachers who also have your students" (1.T7). The principals added that communication must be established not only within the school, but also with the community (2.SP).

Solving Communication Problems. Effective principals resolve student-student conflicts by analyzing the situation and each student's profile. Different strategies are applied: punishment, peer mediation, and involving the family.

Positive Atmosphere, Friendly Relations. With this open communication comes a positive atmosphere which is conducive to collaboration. "Very positive, a lot of collaboration. It's always been there. It's not because we added collaboration teams that it makes a difference. There has always been a lot of collaboration between the teachers" (1.ADE).

Principals of effective schools say that their first priority is everyone's well-being. They consider the school climate as being the foundation as follows:

First of all, at the base of it, the message that I give to the students and to the staff is that we have to strive for everyone's well-being. For me, before anything else, the atmosphere at the school must be a positive one. When the students arrive here, they have to feel as good as the staff. That is my priority. I think the atmosphere in the school is at the heart of everything (5.SP)
The principals we interviewed underlined the importance of keeping a close eye on the school climate, while maintaining high standards of achievement. They went further to say that the atmosphere is not an end unto itself; their role has evolved because they no longer limit themselves to the discipline factor, albeit it is considered as a prerequisite to any environment that is conducive to learning as follows:

One of the things that has changed is that there is perhaps more conversation between principals and teachers regarding student achievement. In the past, the teacher was responsible for that, and we [the principals] took care of the discipline aspect, the smooth functioning of the school, and so on. Well now, we have conversations to help everyone get ahead on the personal growth level and what is best for the student (1.SP)

Nonteaching professionals, such as guidance counsellors and psychologists, are invited to intervene and voice their opinion regarding certain situations. "They really want to get our feedback" (1.CO1).

Bringing Teachers to Commit to the School's Culture. The students feel comfortable to go see their principal to report any abnormal behaviour, whether it is regarding another student or a teacher as follows:

Because he [the principal] closely follows the teacher-student-parent conflicts, because the students are very, very comfortable to go see the principal to tell them that there is something wrong with a teacher, the vice-principal will perhaps come see you and say: "Look, here the school culture is this" (3.T3)

5.5.3. Interpersonal Relations. In the case of conflicts between teachers, the effective principal gets involved to reestablish communication and to resolve problem situations. Several scenarios are proposed.

Principal-Teacher Relations. Following up on certain cases requires open communication between the students and their principal. Such is the case, for example, of the principal's partnership with various regional associations for the funding of a football project involving a third of the boys in the school. The ultimate objective of the project was seeing that the boys all stayed in school and performed academically as follows:

Over 30\% of our students are involved in school sports and regional associations in Québec City. I head this project. Therefore, I have to remain close to the students, and that's a win-win situation all down the line because there is always someone who comes to your office to chat with youwhich is not something you see everywhere.... We communicate to them how we relate to our students, and our meetings with the students. So for sure, they are spoiled with respect to that (2.ADE) 
Good Listeners/Open to Suggestions. The effective principal is willing to listen and can put things into perspective to provide the best possible support for their staff. On various levels, the staff members say that they feel that they are being heard as follows:

\section{As for the teachers, it's a question of being a good listener, because that's what we try to do a lot. What's more, it's what they tell us: that they are very, very satisfied of that. It's because we listen to them, and we also try to give them all that we are able to give with the means that we have at our disposal (2.ADE)}

As for the principals themselves, they are aware that being a good listener is of prime importance, and they invest both time and effort into that as follows:

Being a good listener. Because what I find is that when a school is happy and healthy, quote unquote, a school works well because people are listened to. And that means receiving information, taking the time to stop, to listen to people, and follow-up requests. Otherwise, there's dissatisfaction (3.SP)

The principals described themselves as having the quality of being a good listener, of having a human side and respect of others. They are close to their staff and adopt attitudes that inspire confidence. "The principal is the principal. But at the same time, he is someone else with whom we can talk; maybe not as a friend. . but someone whom we can trust" (2.ADE). These leaders qualified their relations with members of their team as being harmonious, where the people trusted each other and showed mutual support to each other to reach a common objective. One principal compared the members of the school to trapeze artists in the circus. "We support each other just in a circus. There is always someone in motion, like a ball that flies through the air. There is always someone who is falling, but we catch each other. Therefore, trust the team" (1.ADE).

\section{Synthesis and Discussion}

The goal of this study was to study the leadership practices in high-performing high schools located in socioeconomically disadvantaged areas in the Canadian provinces of Ontario, Québec, and New Brunswick. Our results enabled us to identify five underlying themes: (1) establishing goals and expectations, (2) strategic resourcing, (3) curriculum management, (4) teacher supervision and coaching, and (5) ensuring order and support.

6.1. Establishing Goals and Expectations. Our findings show that the school team does strategic planning, and specifically annual operations planning, to ensure its feasibility. This planning involves progress followups and necessary adjustments. Our results concur with the meta-analysis of Robinson et al. [14] and other writings on this subject. In fact, several studies have shown the leadership effect on students outcomes, and particularly the importance of academic and learning objectives [21-23]. The principal achieves this clarity by communicating their objectives and expectations to all of their staff and through a consensus with them regarding these goals $[23,24]$. Effective school leaders involve their teaching staff in the decision making process $[24,27]$ and focus their attention on following up on the progress being made [3].

6.2. Strategic Resourcing. We divided the concept of strategic resourcing into two themes: staff selection and hiring and staff mobilisation. Our results show that the effective school leader focuses their efforts more significantly on staff mobilisation by using four levers: information, power, knowledge, and recognition. These principals make it a point to share information with their staff. For example, they communicate with total transparency and respect regarding each aspect of their teachers' work. They give their staff power by responding to their needs and proposing training activities. They take every opportunity to acknowledge and show appreciation for the work that it is being done. They constantly encourage their teachers to seek out the knowledge needed to do their job and invite them to pursue appropriate professional development in this regard.

While the question of human resources in high-performing schools has not been specifically addressed in the literature, several studies have shown that it is not as much the availability of resources that improves student performance as it is how these resources are managed [42]. Effective principals assign the best teachers to those students who are the most in need [43], provide the necessary assistance and intervention to fully support their teachers [44], offer frequent feedback [45], and participate alongside their teachers in professional development activities [46].

6.3. Curriculum Management. We found that effective principals collaborate with their staff to change, improve, and even create programs. They make their decisions by analyzing their students' needs and by always focusing on maintaining a high level of academic achievement. When delegating duties, they provide their teachers with the necessary support to take on the new responsibilities. These leadership practices are in agreement with many found in several studies on effective schools, which have shown the importance of collaboration between principal and teachers in work-related curriculum reforms [23, 24, 28]. Other authors have shown the importance of teacher empowerment in these effective schools. This empowerment and their involvement in joint decision making appear to be a given in both the school's improvement and student achievement [17].

6.4. Teacher Supervision and Coaching. Our results show that the leadership in effective schools ensures differentiated supervision for their teachers. They also prioritize beginning teachers. This coaching is undertaken according to different modes: the leader themselves, the teachers themselves (selfevaluation), and peer supervision. These leaders make 
the necessary material resources available for their teachers, supervise the teachers' supervisors, and encourage collaborations with peers. Teachers in effective schools attest to their principal's involvement and active participation in their learning and professional development activities [21]. These teachers also say that their principals participate in informal discussions with them regarding teaching and its inherent challenges $[23,24]$. The pole position of the principal in the school's communication network signifies that their advice is more likely to have an influence on the coordination of school activities [29].

6.5. Ensuring Order and Support. The effective principal lays down rules and regulations and condones all forms of violence and bullying. They are reactive but also proactive by raising awareness. They maintain open channels of communication between all of their staff members and keep a watchful eye on interpersonal relations at various levels. They are good listeners and are open to discussion [13].

Various studies show that the effective school leader establishes a safe and supportive environment, protects teachers from undue outside pressure $[23,30]$, and welcomes discussions with their teaching staff $[23,24]$. They quickly and effectively resolve conflicts among the staff [31]. They are attentive and respectful in their interactions with their students $[13,17]$. The atmosphere within the school is positive [13] which is good for morale [17]. These leaders are also appreciative of their staff's work, and they show it [17].

The theoretical model chosen for our study focuses on instructional leadership. While this choice is found to be largely documented by the meta-analysis of Robinson et al. [14], these observations are not new within the context of the three provinces. Such is the case more specifically in Ontario and New Brunswick, where the pedagogical role of principals was defined officially in 2002 and 1999, respectively, with the establishment of teacher evaluation programs. Québec's principals, on the other hand, do have pedagogical duties (the Loi sur l'instruction publique and the Loi sur l'éducation LIP, art.96.12/Chapter E-1.12, 1997), although teacher supervision in this province is reserved for new teachers. The three provinces may differ in this regard; however, one constant remains from the three contexts and pertains to the coaching provided through communities of practice initiatives. In fact, in all three provinces, research on effectiveness increasingly favours collective skills where leadership is a key factor $[5,8,47]$.

Ontario's interest in effective schools is nothing new. Already, in 2001, a study group on effective schools [48] highlighted the importance of pedagogical skills. Among the ten most common denominators found in effective schools, they found seven to be related to the pedagogical dimension: superior quality teaching, schedules that facilitated learning, parents' participation in their children's education, teachers' professional development, established and respected achievement-oriented goals, and regular supervision and followup of the students' progress. This province based its study on that of Leithwood et al. [4] and is strongly committed to school leaders who support their teachers and to research on the phenomenon of effective schools.

\section{Conclusion}

We used several data sources to triangulate the information and collect specific data on leadership practices. Some longitudinal studies facilitate the study of the process used by effective school leaders to achieve better student outcomes. These studies formalise the process of these practices and, as a result, constitute a basis on which to encourage other schools to perform better. Finally, larger-scale quantitative studies provide an interpretation of the results according to certain sociodemographic characteristics, the environment, the school, and the staff.

School principals exercise their duties with a relative amount of freedom. To reach the goals established by the school, they choose certain practices and use different strategies with their staff, their students, and the community. The question remains: to what point do these choices enable them to stimulate student achievement and eradicate failure?

Examining the daily routine of effective school leaders, and in particular instructional leaders, brings us to better understand their effect on student achievement. Many factors in fact contribute to favouring this academic performance: daily interactions in the school; school climate; leadership practices with superiors, staff, students, and community; the staff's daily practices. These practices, however, cannot be transposed as such without considering the particular context of each school.

\section{Acknowledgment}

This work was supported by the Social Sciences and Humanities Research Council of Canada (Grant no. 410-2006-0716).

\section{References}

[1] J. A. Alston, "The many faces of American schooling: effective schools research and border-crossing in the 21st century," American Secondary Education, vol. 32, no. 2, pp. 79-93, 2004.

[2] I. Bogotch, L. Mirón, and G. Biesta, "Effective for what, effective for whom? Two questions SESI should not ignore," in International Handbook of School Effectiveness and School Improvement, T. Townsend, Ed., pp. 93-110, Springer, Boston, Mass, USA, 2007.

[3] D. U. Levine and L. W. Lezotte, "Effective schools research," in Handbook of Research on Multicultural Education, J. Banks and C. McGee, Eds., pp. 525-547, MacMillan, New York, NY, USA, 1995.

[4] K. Leithwood, K. S. Louis, S. Anderson, and K. Wahlstrom, How Leadership Influences Student Learning: Review of Research, The Wallace Foundation, New York, NY, USA, 2004.

[5] Ontario Ministry of Education, "Réforme à grande échelle de l'éducation par le perfectionnement des enseignantes et des enseignants et le développement du leadership dans tout le système," 2008, http://www.edu.gov.on.ca/fre/research/ leadershipCSSE_fr.pdf.

[6] Ontario Ministry of Education, "Diriger la réussite des élèves," 2009, http://www.curriculum.org/LSA/aboutf.shtml.

[7] New Brunswick, Department of Education, "Province takes action in literacy, numeracy and science for francophone students," 2008, http://www.gnb.ca/cnb/news/edu/2008e0571ed .htm. 
[8] Québec Ministère de l'Éducation, du Loisir et du Sport, "Launch and integration of elementary schools and new secondary schools participating in the New Approaches," New Solutions intervention strategy in 2007-2008, 2008, http:// www.mels.gouv.qc.ca/agirautrement/FeuilletSIAA_a.pdf.

[9] P. Hallinger and R. H. Heck, "Reassessing the principal's role in school effectiveness: a review of empirical research, 19801995," Educational Administration Quarterly, vol. 32, no. 1, pp. 5-44, 1996.

[10] D. Reynolds, B. Creemers, S. Stringfield, C. Teddlie, and G. Schaffer, "World class schools," in International Perspectives on School Effectiveness, Routledge-Falmer, London, UK, 2002.

[11] T. Waters, R. J. Marzano, and B. McNulty, "Balanced leadership: what 30 years of research tells us about the effect of leadership on student achievement," Mid-continent Research for Education and Learning, Aurora, Colo, USA, 2003, http://www.mcrel.org/.

[12] K. Leithwood, C. Day, P. Sammons, A. Harris, and D. Hopkins, "Successful school leadership: what it is and how it influences pupil learning," Tech. Rep., DfES and Nottingham, London, UK, 2006.

[13] K. Leithwood, "The emotional side of school improvement: a leadership perspective," in International Handbook on School Effectiveness and Improvement, T. Townsend, Ed., pp. 615-634, Springer, Dordrecht, The Netherlands, 2007.

[14] V. M. J. Robinson, C. A. Lloyd, and K. J. Rowe, "The impact of leadership on student outcomes: an analysis of the differential effects of leadership types," Educational Administration Quarterly, vol. 44, no. 5, pp. 635-674, 2008.

[15] K. Leithwood and B. Levin, "Assessing school leaders and leadership programme effects on pupil learning," DfES Research Report 662, DfES, London, UK, 2005.

[16] J. B. Anderson, "Principals' role and public primary schools' effectiveness in four Latin American cities," Elementary School Journal, vol. 109, no. 1, pp. 36-60, 2008.

[17] H. Silins and W. R. Mulford, "Leadership and school effectiveness and improvement," in International Handbook of School Effectiveness and Improvement, T. Townsend, Ed., pp. 635-658, Springer, Dordrecht, The Netherlands, 2007.

[18] N. Engels, G. Hotton, G. Devos, D. Bouckenooghe, and A. Aelterman, "Principals in schools with a positive school culture," Educational Studies, vol. 34, no. 3, pp. 159-174, 2008.

[19] K. S. Crum and W. H. Sherman, "Facilitating high achievement: high school principals' reflections on their successful leadership practices," Journal of Educational Administration, vol. 46, no. 5, pp. 562-580, 2008.

[20] P. Hallinger and R. Heck, "Next generation methods for the study of leadership and school improvement," in Handbook of Research on Educational Administration, J. Murphy and K. S. Louis, Eds., pp. 141-162, Jossey-Bass, San Francisco, Calif, USA, 2nd edition, 1999.

[21] J. D. Bamburg and R. L. Andrews, "School goals, principals, and achievement," School Effectiveness and School Improvement, vol. 2, pp. 175-191, 1991.

[22] D. J. Brewer, "Principals and student outcomes: evidence from U.S. high schools," Economics of Education Review, vol. 12, no. 4, pp. 281-292, 1993.

[23] R. H. Heck, G. A. Marcoulides, and P. Lang, "Principal instructional leadership and school achievement: the application of discriminant techniques," School Effectiveness and School Improvement, vol. 2, no. 2, pp. 115-135, 1991.
[24] R. H. Heck, T. J. Larsen, and G. A. Marcoulides, "Instructional leadership and school achievement: validation of a causal model," Educational Administration Quarterly, vol. 26, no. 2, pp. 94-125, 1990.

[25] E. B. Goldring and R. Pasternak, "Principals' survival with parental involvement," School Effectiveness and School Improvement, vol. 7, no. 4, pp. 342-360, 1996.

[26] V. M. J. Robinson, "Embedding leadership in task performance," in Leadership For Quality Schooling: International Perspectives, K. Wong and C. Evers, Eds., pp. 90-102, Falmer, London, UK, 2001.

[27] K. Leithwood and D. Montgomery, "The role of the elementary principal in program improvement," Review of Educational Research, vol. 52, no. 3, pp. 309-339, 1982.

[28] H. M. Marks and S. M. Printy, "Principal leadership and school performance: an integration of transformational and instructional leadership," Educational Administration Quarterly, vol. 39, no. 3, pp. 370-397, 2003.

[29] N. E. Friedkin and M. R. Slater, "School leadership and performance: a social network approach," Sociology of Education, vol. 67, no. 2, pp. 139-157, 1994.

[30] R. H. Heck, "Principals'instructional leadership and school performance: implications for policy development," Educational Evaluation and Policy Analysis, vol. 14, no. 1, pp. 21-34, 1992.

[31] R. W. Eberts and J. A. Stone, "Student achievement in public schools: do principals make a difference?" Economics of Education Review, vol. 7, no. 3, pp. 291-299, 1988.

[32] B. Berg, Qualitative Research Methods for the Social Sciences, Allyn \& Bacon, Needham Heights, Mass, USA, 4th edition, 2001.

[33] E. Chambers, "Applied ethnography," in Handbook of Qualitative Research, N. F. Denzin and Y. S. Lincoln, Eds., pp. 851-869, Sage, Thousand Oaks, Calif, USA, 2000.

[34] C. Marshall and G. B. Rossman, Designing Qualitative Research, Sage, London, UK, 3rd edition, 1999.

[35] S. B. Merriam, Qualitative Research and Case Study Applications in Education, Jossey-Bass, San Francisco, Calif, USA, 1998.

[36] C. Werthe, "Élaboration et formalisation de l'expérience professionnelle: l'instruction au sosie," Dialogue, vol. 86, pp. 41-42, 1997.

[37] P. Vermersch, L'entretien d'Explicitation, ESF, Paris, France, 1994.

[38] P. Vermersch and M. Maurel, Eds., Pratiques de l'Entretien d'Explicitation, ESF, Paris, France, 1997.

[39] J. M. Van der Maren, Méthodes de Recherche pour l'Éducation, les Presses de l'Université de Montréal, Montréal, Canada, 1995.

[40] R. E. Boyatzis, Transforming Qualitative Information: Thematic Analysis and Code Development, Sage, Thousand Oaks, Calif, USA, 1998.

[41] M. Miles and M. Huberman, Analyse des Données Qualitatives, De Boeck Universiteé, Bruxelles, Belgium, 2003.

[42] D. M. Daley and M. L. Vasu, "Supervisory perceptions of the impact of public sector personnel practices on the achievement of multiple goal putting the strategic into human resource management," American Review of Public Administration, vol. 35, no. 2, pp. 157-167, 2005.

[43] K. Haycock, "Closing the achievement gap," Principal, vol. 82, no. 2, pp. 20-23, 2002.

[44] V. Myers and C. Kline, "Secondary school intervention assistance teams: can they be effective?" The High School Journal, vol. 85 , no. 2, pp. 33-42, 2002. 
[45] M. D. Chester and B. Q. Beaudin, "Efficacy beliefs of newly hired teachers in urban schools," American Educational Research Journal, vol. 33, no. 1, pp. 233-257, 1996.

[46] D. Fisher and N. Frey, "Five lessons for leaders," Principal Leadership, vol. 3, no. 3, pp. 53-55, 2002.

[47] New Brunswick, Department of Education, "When kids come first. A challenge to all New Brunswickers to built Canada's best education system new vision for public education in New Brunswick," 2007, http://www.gnb.ca/0000/kidsfirst-f.asp.

[48] Ontario Ministry of Education, "Bien faire mieux faire!," Rapport du Groupe sur les Écoles Efficaces Groupe D’Étude sur les Écoles Efficaces, Ontario, Canada. 


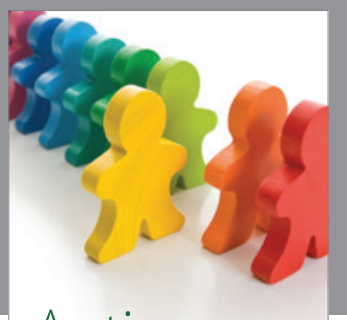

Autism

Research and Treatment
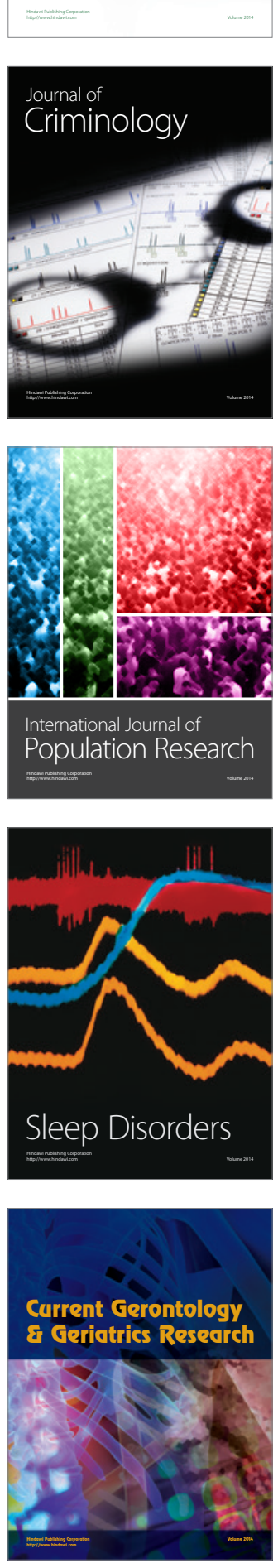
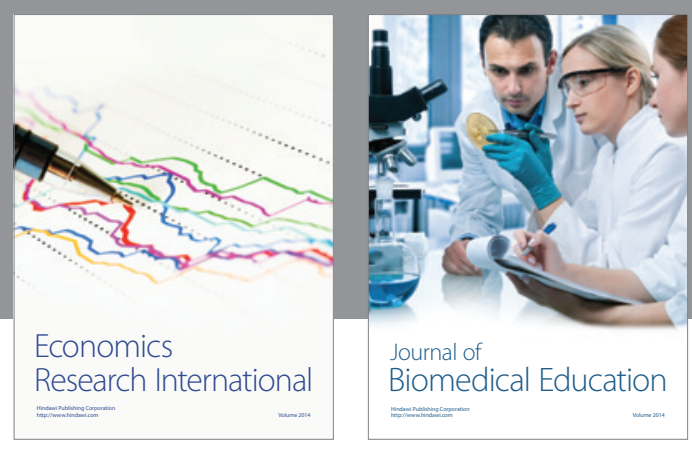

Journal of

Biomedical Education

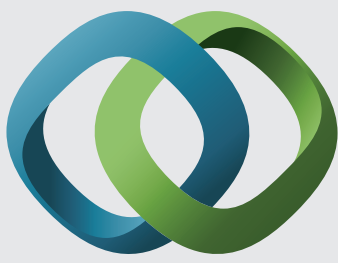

\section{Hindawi}

Submit your manuscripts at

http://www.hindawi.com
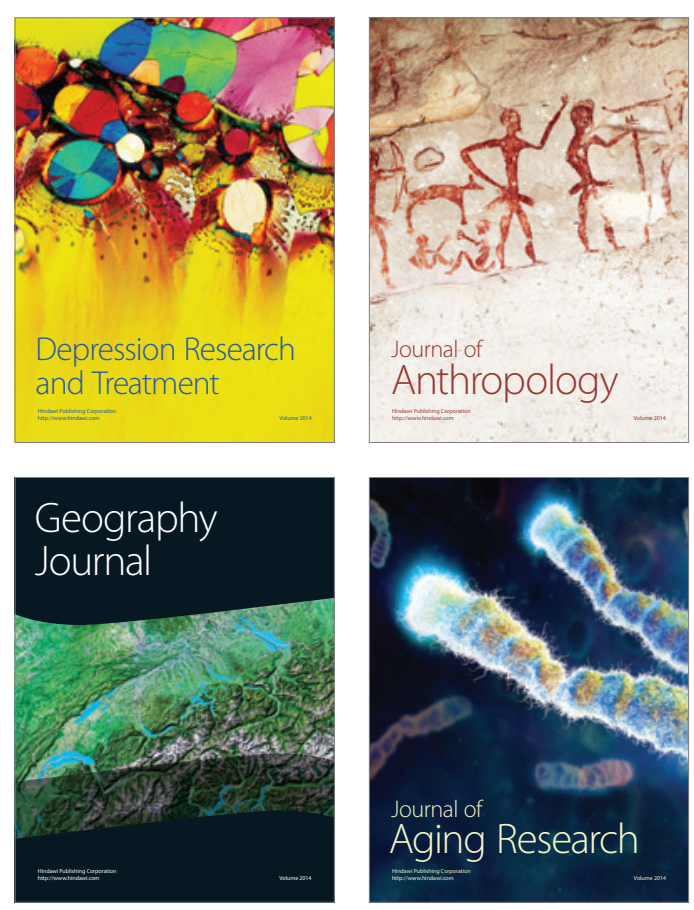

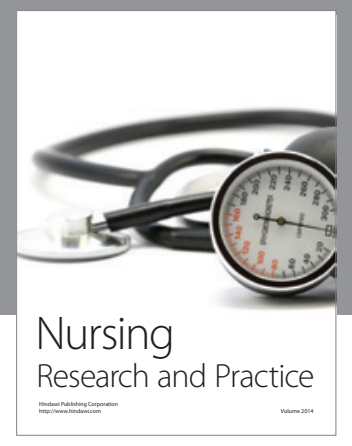

Nursing

Research and Practice

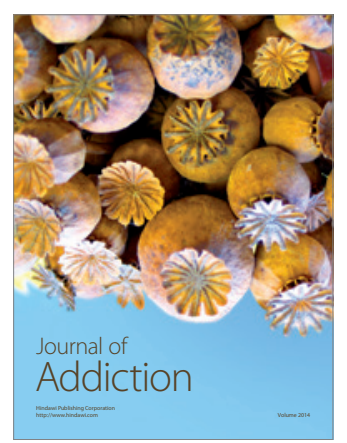

Child Development

Research

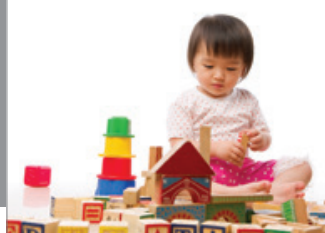

迥
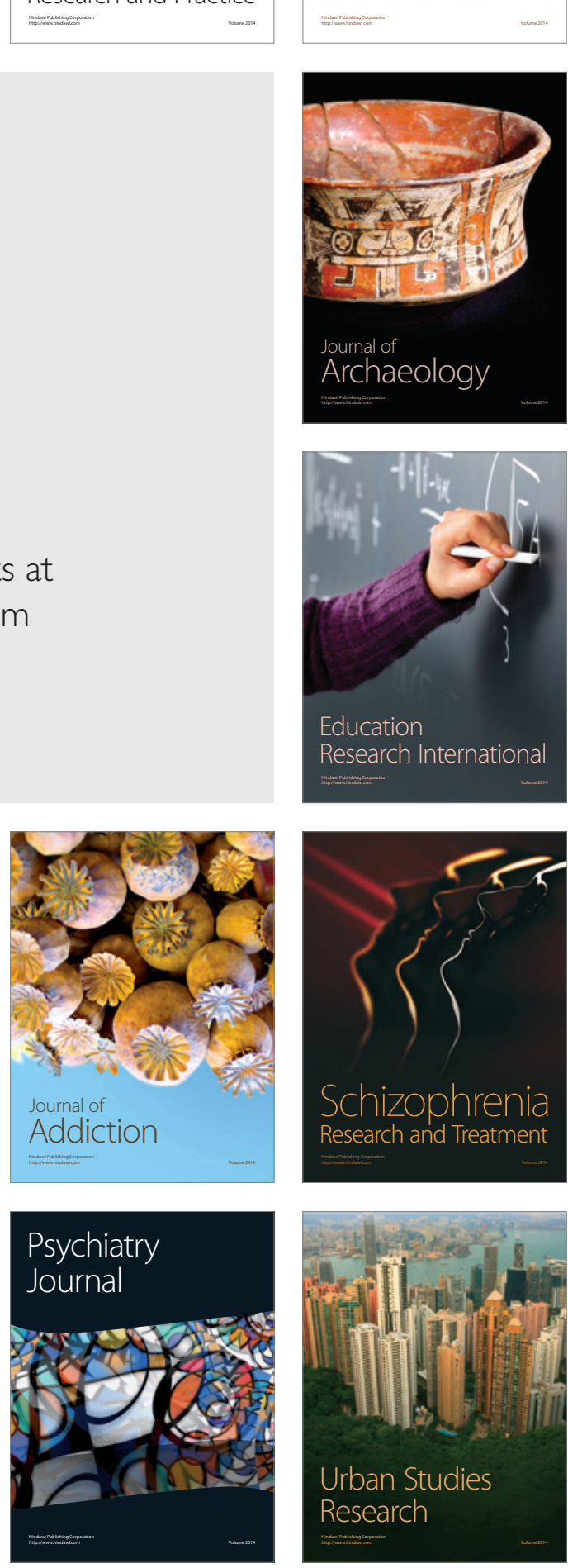